\title{
Homonymy in Jordanian Colloquial Arabic: A Semantic Investigation
}

\author{
Jamal Azmi Salim ${ }^{1}$ \\ ${ }^{1}$ Department of English, Zarqa University, Jordan \\ Correspondence: Dr. Jamal Azmi Salim, Assistant Professor of Linguistics- Department of English, Zarqa \\ University, Jordan. E-mail: jamalazmi1964@yahoo.com
}

Received: May 27, 2013 Accepted: July 19, 2013 Online Published: August 15, 2013

doi:10.5539/ells.v3n3p69 URL: http://dx.doi.org/10.5539/ells.v3n3p69

\begin{abstract}
Homonymy is a major source of ambiguity at the lexical as well as the syntactic levels. It could present a serious difficulty in communication in general as well as in translation in particular. The present paper explores some examples of homonymy in Jordanian Arabic resulting from the diglossic situation prevailing in the Arab world. The inter-relation between Modern Standard Arabic on the one hand and the colloquial dialect on the other hand is a major source of ambiguity in Jordanian Arabic, hence the significance of the present research. The researcher has chosen a set of homonymous words from Jordanian Arabic to be analyzed and the unrelated meanings of such words be pointed out. Such analysis will try to disambiguate the vagueness of meaning that arises from such homonyms while relating it to the phenomenon of diglossia whenever necessary.
\end{abstract}

Keywords: Ambiguity, homonymy, polysemy, colloquial Jordanian Arabic, MSA, diglossia, disambiguation

\section{Introduction}

The various sources of misunderstanding and lack of communication through language have for long been a focus of academic research. A major case in point is the study of ambiguity in human languages. The present research, thus, attempts to explore one of the major semantic phenomena related to ambiguity, viz. homonymy. In recent years, the multi-semanticity of words in natural languages has been discussed at length in the fields of semantics, applied linguistics, psycholinguistics, psychology, philosophy and literature. Following this trend, the study of polysemy and homonymy has gained considerable attention in lexical semantics. (Ullmann, 1962; Cruse, 1986; Palmer, 1995; Nida, 1997), cognitive linguistics (Cuychens and Zawada, 2001; Deane, 1988), discourse analysis (Leech, 1974), language teaching (Todd, 1987), psycholinguistics (Pinker, 1995; Gibbsetal, 1994), stylistics (Lyons, 1963; Allan, 2001) and language and literature (Firth, 1957; Yule, 1985; Cruse, 2000).

\subsection{Significance of the Research}

Information obtained from the analysis of various multi-semantic lexical units has made remarkable contribution in understanding the nature and process of language cognition and acquisition, designing tools and systems for language processing as well as developing strategies for language teaching. In this light, an urgent need arises for investigating the interface between polysemy and homonymy with an expectation that information obtained from this study will help in gaining some insight into the phenomenon to overcome the hurdles of sense disambiguation of words. The significance of the present paper is also derived from the fact that homonymy is the source of ambiguity in the case of Jordanian Arabic. Thus, it should be studied and examined. In addition, homonymy has its own features specification often due to diglossia, a linguistic phenomenon prevailing in the Arab world per se.

\subsection{Objectives of the Study}

Homonymy is a major source of ambiguity, whether intentional or unintentional, that often presents a serious hindrances to the language learner. The difficulty is doubled for students of a foreign language, especially when their own native tongue manifests ample examples of ambiguity resulting from the diglossic situation in Arab communities. This phenomenon, indeed, creates lexical and syntactic ambiguity in all human languages, hinders communication at times, renders translation more difficult than it already is and even makes the life of programmers of machine translation software almost impossible.

\subsection{Hypotheses of the Research}

The researcher believes that homonymy to represent a serious obstacle in communication, especially for 
beginners or foreigners. Furthermore, apart from the general causes of homonymy on the historical and/or etymological levels, the researcher expects a considerable amount of homonyms in Jordanian Arabic to stem from the phenomenon of diglossia in particular.

\subsection{Scope and Method of the Research}

The researcher has chosen a set of homonymous words from Jordanian colloquial Arabic to be analyzed and the unrelated meanings of such words pointed out. Such analysis will try to disambiguate the vagueness of meaning that arises from such homonyms and sheds some light on their diglossic origin. Indeed, homonyms could pose a serious problem whether in translation in particular or in communication in general.

The researcher basically resorts to the analytical/descriptive approach. Arabic lexemes are provided in Arabic as well as a transliteration based upon Romanization of Arabic in ALA-LC Romanization Tables adopted by the Library of Congress as found in the following site: http://www.loc.gov/catdir/cpso/romanization/arabic.pdf.

\section{Review of the Relevant Literature}

The study of ambiguity has for long been a center of attention for linguists in general and semanticists in particular. It is a major characteristic of human languages to have different sorts of ambiguity on top of which comes homonymy and polysemy.

The study of polysemy of a language has often been associated with the study of homonymy. The distinction between the two has often been relatively easy to draw out in theory yet quite difficult to pin down in practice. One is easily misled to assume homonyms as polysemes or vice versa. However, there is a need to draw a clear line of distinction between the two, because these forms differ from each other not only in their nature, but also in function and implication.

There are various and sometimes even conflicting definitions of homonymy and polysemy. The researcher shall attempt a snapshot at the most well-known of these, especially the ones that shall be utilized in this paper.

\subsection{Definitions of Polysemy}

"In polysemy a particular word exhibits variations of its sense depending on the context of its use" (Fellbaum, 2000: 52)." While studying polysemy in a language it may be observed that multiplicity of sense of words is a general characteristic feature of the language" (Palmer, 1995: 108). Almost all natural languages have a set of words that are capable of conveying multiple objects, ideas and senses-both in their context-bound and context-free situations.

"This particular feature of words allows a user to derive more than one sense that may differ in terms of lexical feature, morpho-syntactic feature, sub-categorization feature, semantic feature, lexical selectional feature, idiomatic usage, proverbial usage, and figurative usage" (Sinclair, 1991: 105).

Polysemy is generally defined as "having several, often quite different meanings, all derived from the basic idea or concept" (Dictionary of linguistics, 1954). The lexicographer lists homonymy as different words, whereas polysemy is a term used in traditional semantics for a word that has multiple meanings but all of them are given under one entry by the lexicographer. For example, 'human head', 'head of the department', 'bridge head'. Hence polysemy means that one word can have more than one sense. The distinction between homonymy and polysemy is by and large indeterminate and arbitrary, resting upon either the lexicographer's judgment about the plausibility of the assumed extension of meaning or some historical evidence that a particular extension has in fact taken place.

The most prevalent type of polysemy is the result of ordinary contextual shifts in application. Adjectives are particularly prone to this kind of shift. For instance, we can look at the different meanings of 'red' (Arabic. 'ahmar or fem. hamra:') in 'red ink', 'red deer', 'red cabbage', red flower', 'Red Indian '. Specialization in milieu is another common cause of polysemy, e.g., 'partner' (Arab. shari:k), partner in crime, room partner, business partner', marriage partner. Partner contains the basic meaning of a type of relationship between two (or more) people. But a business partner is not what a marriage partner is. Another, and a very frequent type of polysemy, is that created by metaphor, e.g., human body, heavenly body, body politics, body (of a liquid).

As a matter of fact, it appears that homonymy and polysemy occupy places along a graded continuum of meaning with homonymy at one extreme and vagueness at the other extreme, with polysemy falling somewhere in between. The English word 'cousin' is often cited as a classic example of vagueness resulting from polysemy. On the other hand, a classic example of homonymy would be the difference between 'bank' meaning the side of a river and 'bank' signifying a financial institution, where we have two different lexical items, listed in two different entries in most lexicons and are treated as two distinct lexemes that happen to have an identical form. 


\subsection{Definitions of Homonymy}

Originally, the word 'homonymy' comes form the conjugation of the Greek prefix homo-, meaning 'same', and suffix-onymos, meaning 'name'. Lyons (1982: 72), Oxford Wordpower (2000: 366); Richards and Schmidt (2002: 241); and Yule (2006: 107) define 'homonyms' as a term used in semantics for lexical items that are identical in spelling and pronunciation but have different meanings.

Hartman and Stork (1976: 105; Atchison 1993: 52; and Fromkin et al. 2003: 71) agree that homonyms are different words with the same pronunciation that may or may not be identical in spelling. Thus, they give them a definition that is partially similar to that of homophones. On the other hand, Watkins et al, (2001: 269) define it just like defining homophones, i.e., "words that sound exactly like other words but have different spellings" in spite of the fact of not naming them 'homophones' in addition to 'homonyms' as Fromkin et al (2003: 71) do.

"In case of homonymy, different unrelated senses or meanings are shared under the same surface form of words" (Fellbaum, 2000: 52). Such words often exhibit identical spelling or orthographic forms but are different in meaning. A quick reference to respective meanings and etymology of the forms helps to identify homonyms quite easily in a text. Homonymy, in general is expressed in two broad ways: (a) Homography: identical spelling and different meaning, e.g., mug (drinking vessel vs. gullible person), bank (financial institution vs. the side of a river or a stream), and (b) Homophony: different spelling and similar pronunciation (e.g., no vs. know; peace vs. piece; write vs. right).

"Homonyms are identical in form (i.e., spelling and pronunciation), but different in meaning. They are ambiguous words whose different senses or meanings are far apart from each other and not obviously related to each other in any way" (Farghal M., 1998: 130). Indeed, homonyms could pose a more serious problem whether in translation in particular or in communication in general.

\subsection{Types of Homonyms}

\section{A-Complete homonymy}

Complete homonyms are those that have the same pronunciation and the same spelling i.e., the identity covers spoken and written forms. Classic examples are bank (embankment) and bank place where money is kept) Absolute or complete homonyms are identical in form, all their forms are identical and all their identical forms are grammatically equivalent (Lyons, 1982: 72 and Allan, 1986: 150).

\section{B-Partial homonymy}

If one of the conditions of absolute homonyms is missing, it is a case of partial homonymy. In other words, if one of the forms is not identical or if an identical form is not grammatically equivalent, then it is partial homonymy. A classic example is "found" (past tense of 'find' and 'found' present meaning 'establish' or 'flies' a noun in the plural of a fly and 'flies' present simple tense third person singular of verb 'to fly' (Catford, 1965). Partial homonyms are also sometimes defined as those where the identity covers a single medium, as in homophony and homography. Thus, homophones and homographs are considered partial homonyms (Crystal 2003: 220). Watkins et al. (2001: 269), however, differentiate between homonyms and what they call 'near homonyms'. The present research adopts Lyons' and Crystal's definitions.

Homonyms and polysemes may belong to different parts of speech, i.e., nouns, verbs, adjectives and adverbs. Consider the homonymous and/or polysemous word 'fast' in the following expressions: Peter is a fast typist, Peter types fast, -Peter will fast for ten days, and, Peter will have a ten-day fast. The four instances of fast above are an adjective, an adverb, a verb, and a noun, respectively. The first and second instances of fast are semantically related; hence they are polysemous. Similarly, the third and fourth instances are polysemous for the same reason. By contrast, the senses of these two groups of words of fast are homonymous with each other, because their senses are completely unrelated.

\subsection{Homonymy in Arabic}

Homonymy in Arabic is often referred to as ' attajanus allafdi ' or ' almushtrak allafdi'. Similarly, homonyms are called ' alwju:h wal nada'er' in the Holy Qur'an (Al-Dhamin 1990: 66). In philology, AlSalih (1968: 302) defines homonymy as a word or a sentence that has one articulation (or form) and more than one meaning. For example, the word "sin" has one articulation whether it means 'age' or 'tooth'; and "daqi:q' which means 'flour', precise, and thin. An example of homonymy from Holy Quran ' fala rafatha wala jida:la fil haj" in which 'rafath' may mean to have an intercourse or to say bad words.

\subsection{Types of Arabic Homonyms}

Homonyms in Arabic can be divided into the following types (Abdul Ameer and Areej, 2010: 12-13): 
A. Homonymic words having two meanings, /lisa:n/' organ of body' or ' language', /qadam/' part of body' or ' unit of length'.

B. Homonymic words having multiple meanings,/fasl/' act of a play', chapter of a book', ' season of a year', semester in school or university'; /3ayn/' hole of a needle', 'eye of a person', 'member of the house of lords'; /bank/' money institution' , ' place where blood is kept', 'desk in a classroom at school'.

A well-known example that has different meanings in classical Arabic is the word /hu:b/ which may mean ' sin, need, sadness, heart softness ,sister, daughter, etc. (ya'kuoob, 1999: 178) '

C. Homonymic words with a related meaning, /thira:3/' body organ and unit of measurement'; /yad/'part of a body and power'.

This kind of words is known as polysemy in English (Umer, 1982: 63-4)

D. Homonymic words with unrelated meaning,/qarn/' ' horn of an animal or a period of a hundred years';/nahdi/' my breast' or ' pink color'; /sha:f/" to see' or 'water jar';/fard/' a pistol', or ' an individual';/ibni/' my son' or ' you build'.

E. Words with same pronunciation with different spelling (homophones).

A unique kind of homonymy in which words share the same pronunciation but differ in spelling (i.e. homophony). Examples are follows: /thahab/' he went' or ' gold'; /ma:l/ 'he inclined or money'.

F. Homonyms created because of shift in application: Some words have different senses according to usage, /3amaliah/ ' a surgical operation, execution, action'; /jida:r/' a wall, firewall'.

\subsection{Diglossia}

Diglossia is a term used in sociolinguistics to refer to a situation where two very different varieties of a language co-occur throughout a speech community, each with a distinct range of social function. Both varieties are standardized to some degree, are felt to be alternatives by native speakers and usually have special names. Sociolinguistics usually speaks in terms of a high variety and a low $(\mathrm{L})$ variety, corresponding broadly to a difference in formality: the high variety is learnt in school, tend to be used on TV and radio programmes, in serious literature, etc., and as a consequence has greater social prestige; the low variety is widely used in family conversations, and other relatively informal settings.

"Diglossic situations may be found, for example, in Greek (High: Katharevousa; Low: Dhimotiki), Arabic (High: Classical; Low: Colloquial), and some varieties of German (H: Hochdeutsch; L: Schweizerdeutsch, in Switzerland). A situation where three varieties or languages are used with distinct functions within a community is called triglossia. An example of triglossic situation is the use of French, Classical Arabic and Colloquial Tunisian Arabic in Tunisia, the first two being rated H and the last L" (Crystal, 2003: 138-39).

Jordanian Arabic is a set of dialects of the Levantine Arabic language that are originated in the Jordanian Kingdom and are spoken by Jordanians. Jordanian Arabic has a Semitic language structure, with lexical influence of English, Turkish and French. It is spoken by more than 6 million people, and understood in the Levant as well as the rest of the Arab world. As with all Arab countries, the Hashemite Kingdom of Jordan lives in a state of diglossia where MSA is the official language used in most written documents and the media, while daily conversation is held in different varieties of Jordanian Arabic,viz,Madani,Fallahi, and Badawi. For example, a sentence like ' How are you?' would be used in MSA by educated people as /kayfa haluk?/; in Madani / kayfak/; in Fallahi /chayfak/; and in Badawi /ishlunak/. All these forms convey the same sense and are inflected for number, gender, person, and case.

Table 1. Examples of diglossia

\begin{tabular}{llc}
\hline H variety & \multicolumn{1}{c}{ L variety } & Meaning \\
\hline /Hitha:'/ & / kundara/ and / surmayeh/ & 'shoes' \\
/?anf/ & /khushm/ and / munxa:r/ & 'nose' \\
/shifa:h/ & /shalati:f/ and / barati:m/ & 'lips' \\
/kalsa:t/ & /ijraba:t/ and / jarabi:n/ & 'socks' \\
/kibri:tih/ & /shaxa:ta/, / shaha:ta/ & 'matchbox' \\
/ki:s/ & /shwa:// & 'sack' \\
\hline
\end{tabular}




\begin{tabular}{lll}
\hline /haqi:bah/ & /shantih/ & 'bag' \\
/siki:nih/ & /xu:sah/ & 'knife' \\
/ka:sih/ & /kubayih/ & 'glass, cup' \\
/thahaba/ & /ra:h/ & 'he went' \\
\hline
\end{tabular}

\section{Discussion}

The researcher has chosen the following homonymous words used in Jordanian Arabic for the discussion. The choice has been based upon the frequency of occurrence in everyday communication as well as the spread of use across the Hashemite Kingdom of Jordan, despite dialectical differences between the Northern versus the Southern parts of the country. Only fifteen items have been selected due to limitations of time and space where the present research is concerned. Yet, the researcher maintains that these fifteen lexemes under study are in fact representative of a much wider range of similar homonyms in Jordanian Arabic.

سكني ، نهدي ، سكن ، فار ، فارة ، طاولة ، راحة ، سن ، طاحونة ، شاف ، فرد ، سلك ،خال ، جور ، عين .

The above mentioned lexemes can be grouped under two broad categories as follows:

\subsection{Absolute Homonyms}

$$
\text { سكن ، فارة ، طاحونة ، راحة ، طاولة ، سن ، سلك ، فرد ، جوز ، عين . }
$$

The word /sakan/ means 'residence, tranquility', and ashes or the remains of the fire'. The word /fa:rah/ means 'a computer's mouse, 'a jointer of a carpenter', or ' a female mouse'. As for /tahu:neh/, it means both 'a mill' or 'a molar', while /rahah/ 'rest, ' peace of the mind', palm of hand or 'a kind of sweet'. Another case in point is the lexeme /ta:welah/ which means a table or tavela (a Turkish dice game). Similarly, the lexeme /sin/ means either ' a tooth', 'an age' or ' piece of garlic.

The word /silk/ has two meanings; either 'a wire 'or 'a kind of leaf vegetable". The /fard/ refers to both: 'a pistol or' an individual'. The word /jooz/ again has two meanings: 'a couple', 'a hazelnut' or 'a husband'. The word /3ayn/ may exhibit different meanings: 'an eye', 'a member of the House of Senates, water spring', 'a spy, or 'a hole of the needle".

In the case of سكن ، فارة ، طاحونة ، راحة ، طاولة ، سلك ، فرد ، جوز the origin of homonymy goes back to diglossia. One, at least, of the possible meanings of the homonyms in question is colloquial whereas the other is MSA. This leaves us with an eighty percent (80\%) of the items on the list as cases of homonymy resulting from the diglossic situation in the Arab world in general and in Jordan in particular.

\subsection{Partial Homonyms}

$$
\text { سكني ، نهاي ، فار ، شاف، }
$$

Partial homonyms, on the other hand, differ, not only in meaning,but also in the word class to which each item belongs.

In the case of سكني ، نهدي ، فار ، شاف، the origin of homonymy goes back to diglossia again. The only exception is فار where the two possible meanings exist in MSA too. In the case of the other 3 items, at least one of the possible meanings of the homonyms in question is colloquial whereas the other is MSA. Thus, we have a seventy five percent (75\%) of the items on the list that may be fairly regarded as cases of homonymy resulting from the diglossic situation in the Arab world in general and in Jordan in particular.

The word /sakani/ is either an adjective meaning 'grey color' or a noun+ possessive pronoun ' my residence'. The word /nahdi/ as an adjective ' violet' or a noun+ a possessive pronoun 'my breast'. The word / fa:r /, as a noun ' a male mouse' or as a verb 'boiled'. The word /sha:f/ as a verb (pp) ' saw, or has seen', or as a noun 'a water jar'. The above mentioned kinds of homonyms may be tabulated as follows:

Table 2.

\begin{tabular}{lll}
\hline Homonymy & Word class & Meanings \\
\hline 1. /sakani / & Adjective & (1) Grey color (Noun + Possessive pronoun) \\
& & (2) my residence \\
2. /nahdi / & Adjective & (1) violet (Noun + Possessive pronoun) \\
\hline
\end{tabular}




\begin{tabular}{|c|c|c|}
\hline & & (2) My breast \\
\hline \multirow[t]{2}{*}{ 3. / fa:r / } & Noun & (1) A female mouse \\
\hline & & (2) Boiled or has boiled \\
\hline \multirow[t]{2}{*}{ 4. / Sha:f / } & Noun & (1) A jar or a jug of water \\
\hline & & (2) Saw or has seen \\
\hline \multirow[t]{2}{*}{ 5. /sakan/ } & Noun & (1) A residence or tranquility \\
\hline & & (2) An ash or the remains of the fire \\
\hline \multirow[t]{3}{*}{ 6. /fa:rah/ } & Noun & (1) A female mouse \\
\hline & & (2) A mouse of the computer \\
\hline & & (3) A jointer of a carpenter \\
\hline \multirow[t]{2}{*}{ 7./tahu:nah/ } & Noun & (1) A molar \\
\hline & & (2) A mill \\
\hline \multirow[t]{3}{*}{ 8. /ra:ha/ } & Noun & (1) A kind of sweet \\
\hline & & (2) Some rest \\
\hline & & (3) Peace of mind \\
\hline \multirow[t]{2}{*}{ 9. /tawelah/ } & Noun & (1) A table \\
\hline & & (2) A kind of game' \\
\hline \multirow[t]{3}{*}{ 10. $/ \sin /$} & Noun & (1) A tooth \\
\hline & & (2) An age \\
\hline & & (3) a piece of garlic \\
\hline \multirow[t]{2}{*}{ 11. /silk/ } & Noun & (1) Wire \\
\hline & & (2) A kind of leaf vegetable \\
\hline \multirow[t]{2}{*}{ 12. /fard/ } & Noun & (1) A pistol \\
\hline & & (2) An individual \\
\hline \multirow[t]{5}{*}{ 14. /3ayn/ } & Noun & (1) An eye \\
\hline & & (2) A member of the senate \\
\hline & & (3) A hole of the needle \\
\hline & & (4) A water spring \\
\hline & & (5) A spy \\
\hline \multirow[t]{3}{*}{ 15. /jooz/ } & Noun & (1) A husband \\
\hline & & (2) Couple or pair of things \\
\hline & & (3) A hazelnut or coconut \\
\hline
\end{tabular}

\subsection{The Diglossic Origin of Homonymy in Jordanian Arabic}

A quick examination of the above cited items reveals to us that in all these lexemes that represent clear cases of homonymy, whether absolute or partial, from seventy five to eighty percent (From $75 \%$ to $80 \%$ ) of homonyms under study represent case where at least one of the possible different unrelated semantic units involved in each example results from diglossia. One possible meaning is in MSA, whereas the other or others mainly colloquial.

\section{Findings \& Conclusion}

(1) The present paper has explored some ideas regarding the nature and form of homonymy and polysemy; examined and contrasted their formal and functional differences; highlighted some of the unresolved problems within theoretical understanding of homonymy and polysemy in context of conceptualization and word sense disambiguation, with particular reference to the diglossic situation prevailing in the Arab world.

(2) Homonymy, indeed, does create lexical and syntactic ambiguity in all human languages. It also hinders 
communication, renders translation more difficult than it already is and even makes the life of programmers of machine translation software almost impossible.

(3) Understanding the distinction between homonyms is also quite important in information retrieval, where several relevant documents are presented to a close set of forms, which may be a more perplexing environment than that of automatic translation.

(4) Homonymy as a major source of ambiguity often presents a serious hindrances to the native language speaker, especially where regional dialects and diglossia are involved.

(5) The findings of the present research support the researcher's hypothesis that diglossia is a major source of homonymy in Jordanian Arabic.

(6) The difficulty is doubled for students of a foreign language, especially when their own native tongue manifests ample examples of ambiguity resulting from the diglossic situation in Arab communities.

(7) Understanding as well as furnishing all possible sense variations of words in the lexicon will help overcome various problems in communication in general and in translation in particular.

(8) Finally, the researcher hopes the present research may stimulate other researchers to start from where this paper ends and do extensive academic research work focused on Arabic homonyms that sprout from the linguistic phenomenon of diglossia in the Arab world. If this paper manages to do, it has, then, and only then, achieved its own objectives.

\section{References}

Allan, Cruse. (1986). Lexical Semantics. Cambridge University Press, Cambridge.

As"ad, A., \& Abdul Ameer. (2010). Homonymy in English and Arabic: A Contrastive Study. University of Babylon.

Atichison, J. (1993). Teach Yourself Linguistics. London: Hoddor and Stoughton.

Christiane, D. Fellbaum. (2000). "Autotrophony". In Yael Ravin, \& Claudia Leacock (Eds.), Polysemy: Theoretical and Computational Approaches. New York, Oxford University Press Inc.

Crystal, D. (2003). A Dictionary of Linguistics and Phonetics (5th ed.). Oxford: Blackwell Publishers Ltd.

Farghal, M. (1998). Vocabulary Development and Lexical Relations: A Coursebook. Dar Al-Hilal, Irbid, Jordan.

Frank, R. Palmer. (1995). Semantics. CUP, Cambridge.

Fromkin, V. Rodman, \& Hyams, N. (2003). An Introduction to Language(7th ed.). USA: Heinle, a part of Thomson Corporation.

Geoffrey, Leech. (1976). Semantics, Penguin, London.

George, Yule. (2006). The Study of Language: An Introduction. CUP, Cambridge.

Gramley, S., \& Patzold, K. (1992). A Survey of Modern English. London: Routledge. http://dx.doi.org/10.4324/9780203425978

Hartmann, R., \& Stork, F. C. (1976). Dictionary of Language and Linguistics. London: Applied Science publishers Limited.

John, Lyons. (1963). Structural Semantics. Cambridge University Press, Cambridge.

John, Lyons. (1982). Language and Linguistics. Cambridge University Press.

John, M. Sinclair. (1991). Corpus, Concordance, Collocation. Oxford University Press, Oxford.

Richard, J. C., \& Richard, Schmidh. (2002). Longman Dictionary of Language Teaching and Applied Linguistics. Essex, England: Pearson Education Limited.

Romanization of Arabic in ALA-LC Romanization Tables adopted by the Library of Congress. Retrieved from http://www.loc.gov/catdir/cpso/romanization/arabic.pdf

Word Power. (2000). Oxford University Press.

Watkins, F. C., Dillingham, W. B., \& Hiers, J. (2001). Practical English Handbook (11th ed.). Boston.

الصالح، صبحي.1968. دراسات في فقه اللغه. بيروت.

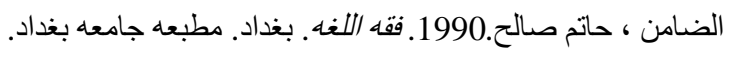

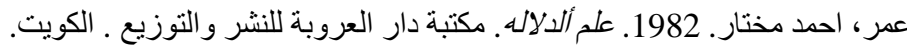


يعقوب، أميل بديع. 1999.فقه اللغة العربية وخصائصها. الطبعة الثانية. الموصل. دار الكتب للطباعة والنشر.

\section{Copyrights}

Copyright for this article is retained by the author(s), with first publication rights granted to the journal.

This is an open-access article distributed under the terms and conditions of the Creative Commons Attribution license (http://creativecommons.org/licenses/by/3.0/). 